Session 2793

\title{
A Model for Faculty Involvement in Closing Outcomes Assessment Loops
}

\author{
Franklin G. King, Keith A. Schimmel \\ North Carolina A\&T State University
}

\begin{abstract}
Two key questions related to implementing the ABET EC2000 criteria are how to effectively use valuable faculty time and how to effectively evaluate outcomes assessment data to make improvements in a program. An outcomes assessment model to address these issues is presented. In this model, faculty time is limited to the evaluation of courses and the review of summarized results processed by administrators and staff. A critical component of the model is the use of course evaluation committees to oversee and manage each of the courses. These committees, composed of 3-4 faculty members, are charged with maintaining and revising the course learning objectives, assessment instruments, and performance targets for each departmental course. The committees are also charged with preparing the course assessment examination in core courses. The current assessment instruments include course exam questions, employer surveys, alumni surveys, student surveys, faculty surveys, advisory board meeting minutes, and advisory board evaluation of limited student portfolios. Based on the assessment results and performance targets, the course committees evaluate whether course learning objectives and program outcomes have been met. The committees make decisions relating to changes in courses and make recommendations relating to program changes to the department outcomes assessment committee.
\end{abstract}

\section{Introduction}

Engineering programs in the U.S. are accredited by the Engineering Accreditation Commission of the Accreditation Board for Engineering and Technology (EAC/ABET) ${ }^{1}$. In the past, programs were evaluated using a set of criteria that prescribed most of the courses and activities that a program had to offer to be accredited. If a department followed ABET's recommendations, their programs were generally accredited. Beginning in 2001, all programs are being evaluated based on the outcomes of the programs and the skills of their graduates. Universities have more freedom to offer innovative programs than before, however, they must convince ABET that their graduates have the set of skills and abilities that are required by the EC 2000 criteria. Each program's outcomes must also be linked to the objectives of the program and the missions of the College and University. In addition to a process for measuring and evaluating their outcomes, Universities must have outcomes assessment (OA) processes in-place to ensure the continuous improvement of the program. The continuous improvement processes must include input from the constituencies that the program serves. This exciting new paradigm in engineering education is presenting many challenges and opportunities for faculty. The assessment challenge was summarized by Denton ${ }^{2}$ as follows: 
"Assessment strategies should not be onerous and bureaucratic in nature, but should be designed to serve the dual purposes of helping each unit reach its goals more effectively and helping the college as a whole to continuously fine tune its collective efforts."

EC2000 has created a new order of doing business in engineering colleges. Tener $^{3}$ states that "the greatest challenge to developing an effective outcomes assessment system is the institutional culture of the faculty." Ewell also concluded that implementation of an assessment plan in which faculty provide and respond to feedback is a difficult task. ${ }^{4}$ Shaeiwitz ${ }^{5}$ states the challenge as follows:

"Implementation of an assessment plan in which faculty provide and respond to feedback will be a difficult task. At most institutions, it will require a significant paradigm shift in faculty behavior. It is unclear how to effect such changes; there are conflicting opinions on whether faculty are motivated by intrinsic or extrinsic factors. But, if this problem is not dealt with forthrightly at the outset, implementation of an effective assessment plan is doomed."

In the academy, the faculty is resistant to change. An important principle for the successful implementation of an assessment process is to minimize faculty time commitment outside their normal course preparation. A second key principle for a successful, sustainable assessment process is to carefully control the data collection and analysis processes so that they can become routine and transparent to the faculty. This is the intent of the outcome assessment model presented here.

\section{Faculty Motivation Factors}

It is generally recognized that the factor most predictive of success in faculty motivation is depth of knowledge about the personal characteristics of the faculty members. ${ }^{6-7}$ Thus, it is difficult to state generalities as to how to motivate faculty to actively participate in program assessment. However, based on available literature, some guidelines are available as to what is most likely to be successful in motivating faculty.

First, faculty are most often intrinsically motivated and have limited positive extrinsic motivation possibilities. ${ }^{7,8-10}$ Thus, the use of financial awards or recognition awards are not as likely to aid the development of a sustainable assessment program as are intrinsic rewards such as the following:

- Seeing positive changes in student performance attributable to faculty actions

- The challenge of continual integration of new information into a course

- Satisfying relationships with students

- Satisfying relationships with colleagues

- A sense of autonomy

- Intellectual stimulation.

In developing an assessment process that utilizes these intrinsic rewards, one needs to be mindful that faculty intrinsic motivation is reinforced by slightly imbalancing the challenge to the faculty 
with the skills the faculty have to meet the challenge. ${ }^{9}$ Thus, whatever new things faculty are being asked to do within an assessment process can be challenging, but must stay within their comfort zone.

The above instrinsic rewards will be most effective as motivators for faculty to participate in an assessment process if the time between implementation of changes and positive results from those changes is short. With this in mind, the assessment process described here has been designed such that the assessment loop from initial measurement to implementation of changes to measurement of the effect of the changes can be accomplished in a year. It is important that department and college administrators be supportive of and help facilitate this short-time-frame loop. Failure to do so can lead to loss of faculty motivation as they perceive that they are just generating a paper trail that is a waste of time because it does not lead to program improvements.

The assessment process outlined here has been designed to stimulate faculty discussion of course content, teaching methods, and how student learning may be improved. Obviously, this requires an atmosphere of trust and respect among department faculty. The process also attempts to increase faculty accountability for student learning while maintaining an atmosphere of faculty autonomy. Obviously, this is a difficult balance to successfully achieve. Improperly implemented, the assessment process presented here can fail due to faculty fear of losing their academic freedom.

\section{Outcomes Assessment Process Model at A\&T}

The engineering programs at A\&T have worked over the past couple of years to establish outcomes assessment processes to meet $\mathrm{ABET}$ requirements. In addition to principles mentioned earlier, principles that guided the development and implementation of our OA processes were to

- Make our plan effective so we could see improvements in our program

- Involve faculty at each step in the development process

- Have a non-administrative faculty champion have a key role in the development

- Make it sustainable so the plan will operate continuously and not fall apart after the ABET visit

- Carefully control the amount of data collected

- Provide summarized results to faculty

- Empower faculty committees to oversee our courses and our curriculum

- Empower faculty to make course and program improvement decisions.

After considerable discussion, the chemical engineering faculty agreed to the concept of having a course committee oversee the operation and assessment of each of our courses. They also agreed to a phase-in of committee control of course activities and a carefully defined implementation on the assessment plan. They agreed and understood that the plan would be changed each year to eliminate items that were not effective and to add procedures to make it work better.

The processes established to review our educational objectives are part of our overall outcomes assessment process. The academic year timeline for executing our overall outcomes assessment processes is given as an Appendix. A schematic diagram of our Assessment processes, Fig. 1, is 
similar to the two loop diagram proposed by ABET. The feedback loops involving the courses and the program are imbedded in the faculty assessment loop. The loop for the assessment of courses will be discussed later.

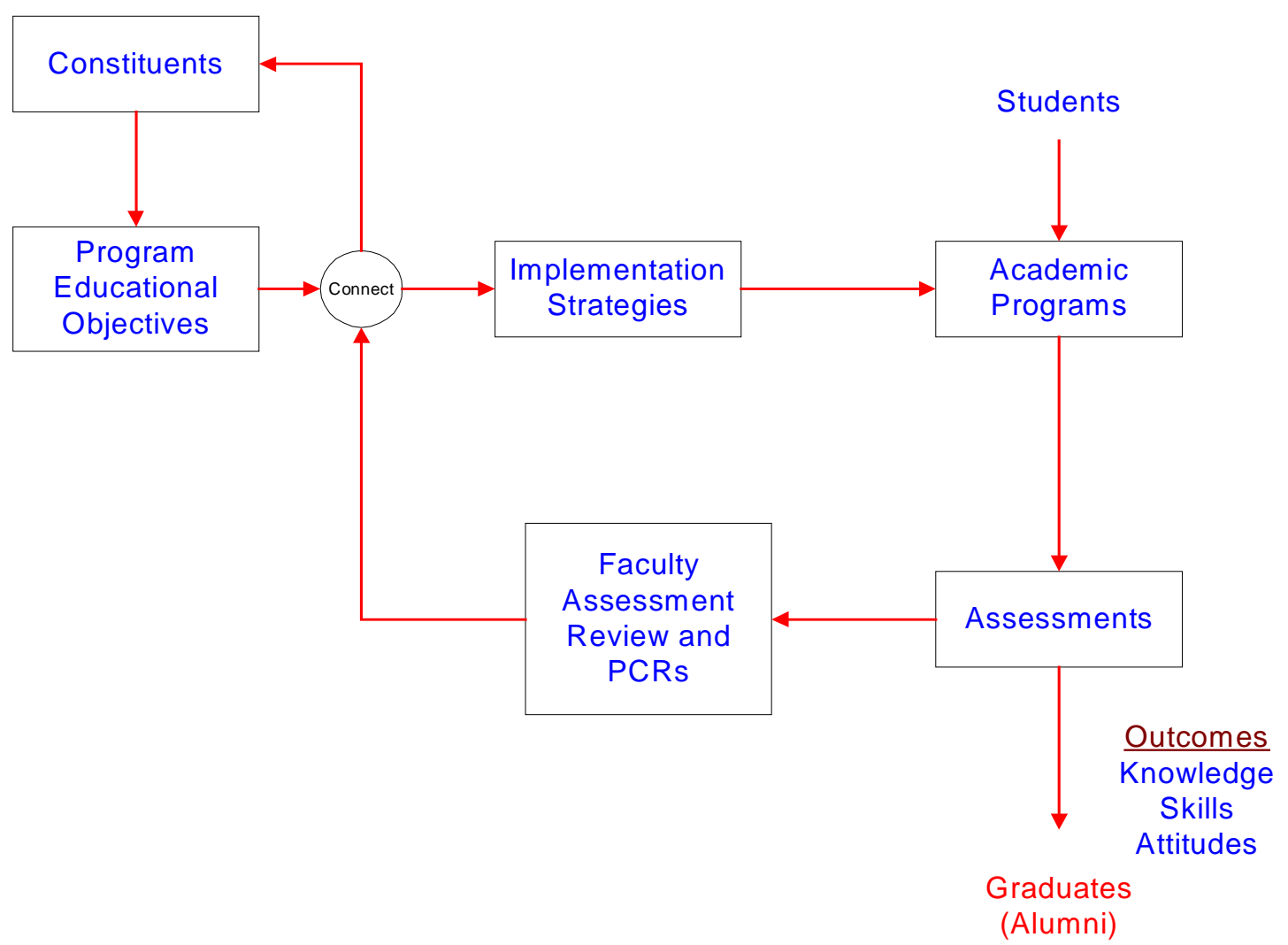

Program Improvement Process Model

Figure 1. Program Improvement Process Model

The program educational objectives were established by the chemical engineering faculty a number of years ago and have been reviewed annually as part of our faculty retreat, but seldom changed. The concept of establishing program constituencies and involving them regularly in the review of objectives was first completed during the 1998-1999 academic year. The program constituencies were identified and approved during that academic year. Outcomes assessment (OA), however, was still in its infancy and confusing to all of us. In addition, most of the faculty had not bought in to the need for OA, because it involved trust in their peers, losing some of their academic freedom, and lack of confidence in ABET's constantly changing criteria. Most of the 1998-99 academic year was spent in learning about OA and conceiving a starting plan. A few faculty included learning objectives in their courses and tried to implement the assessment of the learning objectives. 
Transfer of Academic Freedom: During the fall semester of 1999, department wide OA was implemented. The faculty adopted the following phase-in plan of course assessment and curriculum review in chemical engineering:

1. The first time each chemical engineerng course is taught, the faculty instructor will determine

a. all topics to be included in the syllabus

b. the course text book

c. all learning objectives for the course

d. all questions for the Course Assessment Test (CAT exam), if applicable

e. all faculty are encouraged to consult with other faculty about course topics

2. The second time the course is offered, the faculty member must consult with the committee with regard to items $2 \mathrm{a}-2 \mathrm{~d}$, but can make the final decision.

3. The third and each subsequent time the course is offered, the committee will determine items

$2 \mathrm{a}-2 \mathrm{~d}$.

4. The committee will determine all items whenever a course is taught by an adjunct faculty.

5. All core undergraduate courses will be taught by regular, full-time faculty.

Course Assessment Committees: Each chemical engineering course assessment committee consists of at least three faculty members. These members include the instructor(s) that most often teaches the course and other faculty interested in the course content. Each committee has a coordinator that is knowledgeable in the subject area, but not the instructor who typically teaches the course. The coordinator is responsible for (1) scheduling a committee meeting during the first week of classes following the semester in which the course is taught, (2) making sure that course materials are available for the committee when it meets, (3) keeping the committee discussions on task, and (4) submitting the annual course report.

The purpose and philosophy of the course committees is to stimulate discussion among faculty members and to assess course materials, thereby, leading to documented improvement of course content, student learning, and coordination of content between courses. Toward this end, the responsibilities of the committees are:

1. To specify the assessment instruments for the course.

2. To specify the performance targets for assessing the outcomes for the course learning objectives.

3. To determine if the course syllabus was covered.

4. To determine if the course design content was met.

5. To evaluate the data from the assessment instruments to determine if the course outcomes have been met.

6. To specify the minimum course learning objectives. These objectives should reflect the desired design content of the course. Additional objectives may be added at the discretion of an individual faculty member teaching the course.

7. To select the course text(s) and software packages. 
8. To prepare the Course Achievement Test (CAT) questions (The CAT exam is part of the final exam in chemical engineering core courses. It is prepared by the committee to aid the determination of whether the course learning objectives were met.)

9. To annually review the course and recommend changes regarding the course by completing the annual course report based of the instructor's report and assessment. This report goes to the Department Outcomes Assessment Committee.

The responsibility for the evaluation, maintenance and improvement of our courses and curriculum lies with the faculty. The processes that we have put into place detail how the faculty monitor our courses and curriculum. It also provides the timelines and information models that give the faculty the data needed to make process improvement decisions. The most important loops in our continuous improvement processes are the loops that evaluate student learning in our courses and our overall curriculum. The responsibility for the improvement of the outcomes from our courses lies with the course assessment committees. The flow model depicting the course improvement loop is given in Fig. 2.

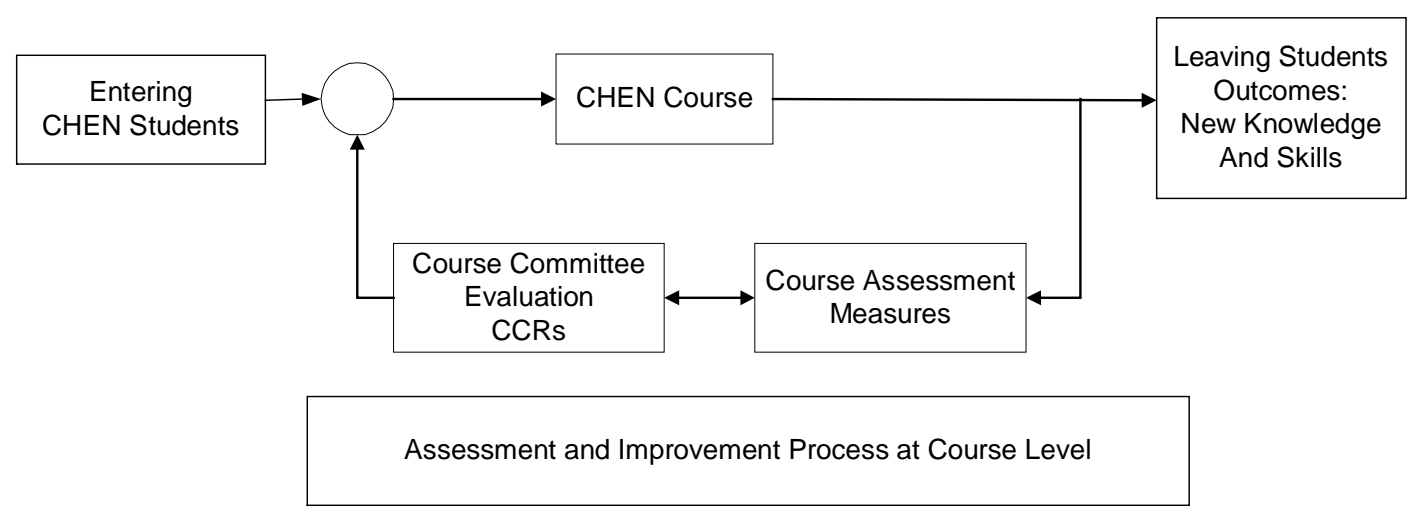

Figure 2. Course Improvement Process Model

Department OA Committee: The management of the overall OA and program improvement processes is the responsibility of the Department OA Committee. The Department OA Committee consists of the Department Chairperson, the Department OA Coordinator, who is a full-time faculty member, and at least one additional faculty member. The flow model depicting the overall curriculum and program improvement loop is identical to the course loop except it encompasses the entire program rather than a single course. The charge to this committee is to determine if there are curriculum wide changes that should be recommended to the entire faculty or if any changes proposed by courses committees affect another part of the program. The committee makes annual reviews of the following:

- Most recent Alumni/Employer survey results

- Chemical engineering graduating student exit survey results

- Annual course committee reports

- Chemical engineering senior comprehensive exam results.

Proceedings of the 2001 American Society for Engineering Education Annual Conference Exposition Copyright (C) 2001, American Society for Engineering Education 
The committee is also responsible for reviewing and maintaining all departmental outcomes assessment instruments and summarizing performance criteria. In addition, the committee reviews course assessment committees and appoints the course coordinators.

Assessment Instruments and Performance Targets for Achievement of Outcomes and Learning Objectives: Performance target levels were set arbitrarily for the first OA cycle. The adjustment of performance criteria for meeting each of the course learning objectives was charged to the individual course committees. An overall check on the target levels is made by comparing the instructor's evaluation of whether a learning objective is accomplished to the conclusion from the performance target. If current performance targets indicate that a learning objective was accomplished, but the instructor of a course indicates that they were not, the target levels need to be adjusted upward.

A significant fairness issue for faculty is that the accomplishment of learning objectives be normalized for the ability level of students in a class. Thus, another check on the target levels is a longitudinal comparison of the overall GPA of the students in the course. It is to be expected that a course offering to a class with a significantly lower GPA than another offering should accomplish fewer of the learning objectives. If this is not the case, the expected cause of the anomaly is a difference in effectiveness between different instructors or a difference in standards between two instructors.

The assessment instruments and typical performance targets for achievement of course learning objectives are:

- Course Survey Results - The target was the percentage of the students taking a course who agreed or strongly agreed that the learning objective was met: $>60 \%=$ Met, $50 \%=$ Partially met, $<40 \%=$ Not Met.

- Exam Question Results - The target was the average score on a regular exam question or CAT exam question designed to demonstrate accomplishment of the objective: $>70 \%$ $=$ Met, $50 \%=$ Partially Met, $<40 \%=$ Not Met.

- Oral Presentation Assessment - The target was the percentage of students rated as having satisfactory oral communication skills using a rubric designed to evaluate accomplishment of the skill: $80 \%$ of students should have satisfactory oral communication skills.

- Lab Report Assessment - The target was the percentage of laboratory reports rated as meeting reporting skills using a rubric designed to evaluate accomplishment of the skill: $80 \%$ of the laboratory reports are rated as meeting the required skills.

- Course Project/Design Assessment - The target was the percentage of students rated as having satisfactory skills to complete the course project or the skills needed to complete the design of a process component design using a rubric designed to evaluate accomplishment of these skills: $80 \%$ of the project reports are rated as meeting the required skills.

Faculty decided that the OA plan needed to have a quantitative evaluation of student outcomes at the program level that is made by an external body representing the employers of our students. 
The plan developed includes the selection of samples for student work as they exit the program and having the selected student work evaluated by the departments external advisory board using department approved performance rubrics. The current plan calls for the evaluation of student achievement of the following skills:

- Oral Presentation Assessment - Each group in the fall semester, senior laboratory will have one lab presentation videotaped.

- Lab Report Assessment - Each group in the fall semester, senior laboratory will have one lab report copied by the senior laboratory instructor.

- Capstone Design Assessment - Representative senior design reports will be selected by the course instructor.

The assessment instruments and performance targets for achievement of program outcomes and current performance targets are:

- Outcomes Achievement Survey: $80 \%$ agreement by graduates, alumni, faculty and the advisory board that graduates have average or better abilities.

- Oral Presentation Assessment: 80\% of our graduates should be rated as having satisfactory oral communication skills.

- Lab Report Assessment: 80\% of the laboratory reports are rated as meeting the required skills.

- Capstone Design Assessment: 80\% of the capstone design reports are rated as meeting the required skills.

\section{The Decision Process}

The decision process can begin at the course level for course related decisions or at the OA Committee for other decisions. The department staff creates and administers a student survey for each course to assess the course learning objectives and the relationship to program outcomes based on committee approved materials. The department staff then posts the survey results and the average grade point average of course students into the draft of the course instructor's report. Course instructors post their course assessment results in the report. They are expected to use at least three metrics for each learning objective. Course instructors then complete their reports by summarizing their results and making recommendations to the course committee for review. Each of the course committees meets to assess the course outcomes, decide on any changes, and recommend that the changes be implemented. Recommended changes involving only the course being evaluated are implemented directly as a course change recommendation (CCR).

Recommended changes involving other courses, or a curriculum change, are forwarded to the OA committee for review as a program change recommendation (PCR). The OA committee evaluates all committee CCRs and PCRs. The OA committee presents program modifications for the entire faculty to review. Program changes are then processed through the existing University infrastructure. 


\section{Findings and Changes Resulting from OA Processes}

Most of the course committees were operational by the end of the first required OA cycle, but the quality of instructor's reports varied from not done to excellent. All of the faculty have made contributions to our OA processes during this, our third year, of OA. All of the faculty feel that their workload has increased and some do not like the new level of accountability. Every course committee made and implemented at least one course change recommendation. The following list summarizes many of the recommendations that have been made by our course committees by the end of the first cycle:

- The learning objectives were modified for all courses

- The text was changed in two courses

- Instructor changes were recommended in two courses

- Required problem sessions were requested in several courses

- Instructors strayed from the curriculum in several courses

- Statistics content of three courses was not reliably covered

- Mass transfer topics in our heat transfer course were generally not covered properly

- Better correlation is needed between the topics assessed in the senior comprehensive exam and the course learning objectives in the core topics courses

The following program changes have been made as a result of OA measurements made by our program:

- A Colloquium course was adopted to improve communication with students

- Classroom teaching content is changing in most courses

- Faculty agreed to include homework problems in safety in most chemical engineering topics courses

- A new course in process data analysis and experimental design has been adopted

- Faculty agreed on a plan for using ASPENPLUS chemical process simulator across the program

- A plan to replace the use of FORTRAN with MATLAB has been approved

- Faculty agreed on a list of courses which require significant use of computers.

\section{Summary}

The purpose of this paper is to describe a model for gaining faculty involvement for successfully implementing and maintaining outcomes assessment processes in an engineering department. In our view, the essential ingredient to implementing and maintaining effective outcomes assessment processes lies with building the involvement and support of the faculty. The model presented here empowers the faculty through our course committees to strive to continuously improve our program. The model has been used by another program at our university and is being implemented to improve our common engineering courses. The model can serve as a guide or a source of ideas for other engineering programs that are working to implement continuous improvement processes in their programs. 


\section{Bibliography}

1. Accreditation Board for Engineering and Technology, Inc. (2001), "Accreditation Policies and Resources," www.abet.org.

2. Denton, D.D. (1998), "Engineering Education for the $21^{\text {st }}$ Century: Challenges and Opportunities," Journal of Engineering Education, vol. 87, no. 1, pp. 19-22.

3. Tener, R. K. (1999), "Outcomes Assessment and the Faculty Culture," Journal of Engineering Education, vol. 88, no. 1, pp. 65-71.

4. Ewell, P. T. (1998), "National Trends in Assessing Student Learning," Journal of Engineering Education, vol. 87, no. 2, pp. 107-113.

5. Shaeiwitz, J. A. (1996), "Outcomes Assessment in Engineering Education," Journal of Engineering Education, vol. 85, no. 7, pp. 239-246.

6. Wergin, J.F., Mason, E.J., and Munson, P.J. (1976), "The Practice of Faculty Development: An ExperienceDerived Model," Journal of Higher Education, vol. 47, pp. 289-308.

7. Sloan, E.D. (1989), "Extrinsic versus Intrinsic Motivation in Faculty Development," Chemical Engineering Education, vol. 23, pp. 134-137, 187.

8. McKeachie, W.J. (1982), “The Rewards of Teaching," in New Directions for Teaching and Learning: Motivating Professors to Teach Effectively, Jossey-Bass, San Francisco, pp. 27-35.

9. Csikszentmihalyi, M. (1982), "Intrinsic Motivation and Effective Teaching: A Flow Analysis," in New Directions for Teaching and Learning: Motivating Professors to Teach Effectively, Jossey-Bass, San Francisco, pp. 15-26.

10. Deci, E.L. and Ryan, R.M. (1982), "Intrinsic Motivation to Teach: Possibilities and Obstacles in Our Colleges and Universities," in New Directions for Teaching and Learning: Motivating Professors to Teach Effectively, Jossey-Bass, San Francisco, pp. 27-35.

\section{FRANKLIN KING}

Franklin G. King is a Professor of chemical engineering at North Carolina A\&T State University. He is also the department Chairman. King received his BS, MS and D.Sc. degrees from Penn State, Kansas State and Stevens Institute. King also holds a M.Ed. degree from Howard University.

\section{KEITH SCHIMMEL}

Keith A. Schimmel is Associate Professor of chemical engineering at North Carolina A\&T State University. Dr. Schimmel is a registered professional engineer in North Carolina. He received a BS degree in chemical engineering from Purdue University. He also holds MS and PhD degrees in chemical engineering from Northwestern University. 


\section{APPENDIX}

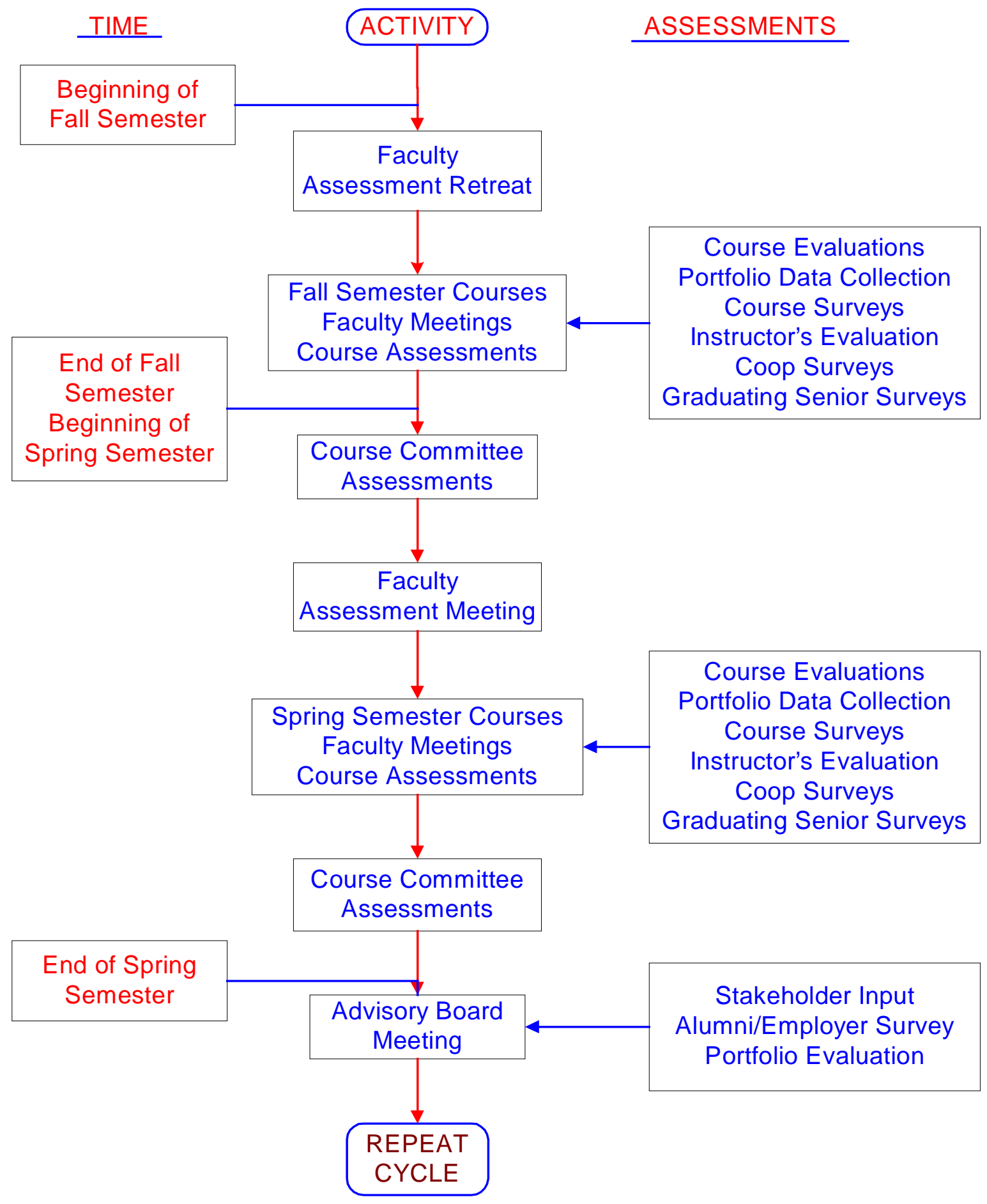

Program Improvement Process and Assessment Timeline 